\title{
Value orientations of students with different levels of general communicative tolerance
}

\author{
Oksana Nikolenko ${ }^{1 *}$ and Lyudmila Zheldochenko ${ }^{2}$ \\ ${ }^{1}$ Don State Technical University, 346780, Russia, Rostov-on-Don \\ ${ }^{2}$ Southern Federal University, 344006, Russia, Rostov-on-Don
}

\begin{abstract}
The article analyzes the role of the value component and lifemeaning orientations in the formation of tolerance. Features of life meaning and value orientations of psychology students with different levels of communicative tolerance. The importance of the formation of communicative tolerance in students. The article presents the results of an empirical study of the features of value and meaning-life orientations in psychology students with different levels of general communicative tolerance. The study was attended by students of DSTU and SFU in the number of 60 people. Students of the humanities (psychologists) were selected. Of these, 35 are girls and 25 are boys. The age of the respondents is from 18 to 22 years. To confirm the hypotheses based on the assumption that differences in life-meaning and value orientations can be found in psychology students with different levels of general communicative tolerance, we used a set of methods: the method "General communicative Tolerance" by V. V. Boyko, the method of "Life-meaning orientations" modified by D. A. Leontiev, the questionnaire "Value orientations" by M. Rokich. It is empirically established that there are significant differences in the meaning-life and value orientations of psychology students with different levels of general communicative tolerance.
\end{abstract}

\section{Introduction}

Modern transformations in society, the processes of globalization, migration of the population affect the value and semantic attitudes of young people. In conditions where the old values no longer work, where you can notice the conditions of social instability, students are in search of new life orientations and strive to adapt them to the conditions of their lives. In the socio-cultural environment, meaning-life orientations are formed, thanks to the assimilation of social experience. First of all, they manifest themselves in goals, beliefs, ideals, and many other aspects of a person's consciousness and guide behavior and personal development. They determine a person's life path, self-determination, and potential in the present and future.

The value-semantic sphere was studied by V. Frankl, L. S. Vygotsky, A. G. Asmolov [1], I. V. Abakumova [2], D. A. Leontiev [3,4], A. A. Bodalev, V. E. Chudinovsky, B. S. Bratus, A. K. Belousova [5], F. E. Vasilyuk, S. L. Rubinstein, M. Rokich, D. Uznadze, etc. Different

\footnotetext{
*Corresponding author: nikolenko.of@mail.ru
} 
psychological schools agree that value orientations act as a personal category, they determine the behavior of an individual and are part of the structure of a person's personality. If a person accepts certain values of society, then he considers these values as part of his personal system and follows them. Meaning as a life reference point of a person, as the main life value, is considered by A. A. Bodalev, who says that the meaning of life is the greatest and most significant value in a person's life. The presence of meaning becomes especially important for people in extreme situations, when the internal reserves of the individual are involved, there is a transition from the "everyday" to the "higher Self" (Bodalev A. A., 1982). "The value-semantic sphere of the individual is formed, transformed and expressed in the process of educational or professional activity. Objective contradictions of modern education allow us to turn to the value-semantic approach in education. In our opinion, the effective formation of the value and semantic sphere of students is ensured by the implementation of a number of psychological and pedagogical conditions [6]." In many respects, the success of the formation of the value-semantic sphere of students will depend on the values of the teachers themselves $[6,7,8,9,10]$, on the " effective meaning transfer of teachers [9]", on the personal and professional characteristics of teachers " who possess innovative methods and technologies, are ready for constant professional growth, self-development and selfactualization [7]".

Currently, there is an increase in the attention of researchers to the problem of communicative tolerance (A. G. Asmolov [1], I. V. Abakumova [2], D. A. Leontiev [3], A. A. Rean, G. U. Soldatova, V. Boyko, R. R. Valitova, I. V. Vlasova, V. A. Lektorsky, L. A. Nikolaeva, O. B. Scriabina, G. P. Shchedrovitsky, etc.). One of the most important tasks is the formation of personality and the formation of tolerance as a personal characteristic, through the formation of value-semantic orientations. The very principle of a tolerant attitude towards others is welcomed in a modern civilized society. This is a kind of compromise that is necessary when interacting in the modern world, since we have to deal with people of different tastes, views, and values. This feature helps to avoid various social conflicts, including ethnic and national tension. D. A. Leontiev says that "tolerance is a form of relations to something different, which does not coincide with my individual characteristics, and with the forms of culture that are familiar to me" [3]. A tolerant attitude is typical only for a strong and mature personality, or a culture that does not see a threat to itself in the fact that other social groups adhere to other values. A weak or failed personality is intimidated by this, and this leads to an intolerant attitude $[3,11]$.

In the scientific literature, the problem of value orientations is studied from different angles:

Ananyev B. G., Bozhovich L. I., Kovalev A. G. Platonov K. K. and others considered value orientations as the orientation of a person to values. Zdravomyslov A. G., Nadirashvili Sh. A., Uznadze D. N., Yadov V. A. and others presented value orientations as the highest level of fixed personal attitudes. Abdulkhanova-Slavskaya K. A., Bodalev A. A., Bratus B. S., Lomov V. F., Slobodchikov V. I. and others considered value orientations as the dominant attitude to environmental objects based on their personal significance. There are also three theoretical directions: objective-idealistic, in which value appears as an existing supraindividual reality (T. Parsons, E. Spranger, N. Hartman, M. Scheler, etc.); subjectiveidealistic, considering value as a subjective relation of a person to the objects being evaluated (G. Allport, K. Rogers, E. Durkheim, etc.). and naturalistic theories, in which value appears as an expression of natural needs and interests of a person (J. Dewey, R. B. Researchers have identified many factors that influence the formation of value orientations. But with the passage of time and the transformations taking place in modern society, one or another stage of historical development has its own characteristics. Thus, it is necessary to highlight the features of the value orientations of modern youth: 1) age-demographic; 2) ambivalenttransitive; 3) educational; 4) deviant-delinquent. 
M. Rokich divided the values of the individual according to their functional significance into two main groups: terminal and instrumental, acting, respectively, as personal goals and means of achieving them. Rokich, 1973). A. Maslow subdivided values depending on the focus on personal development or on the preservation of homeostasis, into higher (development values, existential values) and regressive (preservation values). At the same time, terminal and instrumental, higher and regressive, internal and external values may correspond to different levels or stages of personal development.

V. Frankl, L. S. Vygotsky, A. G. Asmolov, I. V. Abakumova, A. A. Bodalev, B. S. Bratus, D. A. Leontiev, V. V. Stolin, A.V. Petrovsky, T. P. Skripkina, V. E. Chudnovsky, and others studied the problem of the meaning of life, meaning of life orientations of the individual. Meanings can't be invented, they are given by life itself. The meanings can be diverse, but there must be an existential meaning of the existence of a particular person. Everyone will have their own way, it is impossible to bring it from outside. But it is possible and necessary to give certain guidelines to young people, to help in the formation of values. D. A. Leontiev operationalized the theory of striving for meaning by V. Frankl in the method of Meaninglife orientations ( $\mathrm{SSO}$ ), where it is possible to measure the temporal localization of meaning that determines the overall level of meaningfulness of life, focusing not on certain events, but on the attitude of a person to life as a holistic phenomenon. Dmitry Leontiev points out that the concept of meaning "is also correlated with objective (group, communicative) reality, and is also located at the intersection of activity, consciousness and personality, linking all three fundamental psychological categories" [2]. He believes that there is a certain semantic reality of a person's relationship with the world, manifesting itself in different forms, any changes in meaning are associated with a real change in a person with the world. Leontiev connects the concept of meaning with the concepts of regulation and self-regulation.

Communicative tolerance and its formation through the formation of value-semantic orientations and attitudes are studied by A. G. Asmolov, I. V. Abakumova, D. A. Leontiev, A. A. Rean, G. U. Soldatova, V. Boyko, R. R. Valitova, I. V. Vlasova, V. A. Lektorsky, M. T. Gromkova, V. M. Grishuk, P. F. Komogorov, etc. Tolerance as a quality of personality allows students to successfully build interpersonal interactions. And also have high stress resistance. A. G. Asmolov considers communicative tolerance as a characteristic of the individual with a complex structure, which includes the motivational-value, cognitive, emotional, and behavioral components [1].

V. V. Boyko understands communicative tolerance as a characteristic of the relationship of personality to people, the degree of transferability of its unpleasant mental States, qualities and actions of the partner in communication. According to V. V. Boyko [12], it is possible to distinguish several levels of communicative tolerance:

1) Situational-fixed in the relationship of this person to a specific other person (spouse, colleague, patient, etc.);

2) typological-it is revealed in the relation of a person to collective personality types or groups of people, representatives of a particular nation, profession);

3) professional-manifests itself in the collective types of people with whom you have to deal by occupation;

4) general communicative tolerance - the attitude towards people in general, the tendencies caused by life experience, attitudes, character traits, moral principles, the state of mental health of a person.

I. V. Abakumova speaks about the need to pay attention to the formation of tolerance as a psychological and value norm. Since communicative tolerance is one of the core characteristics of the individual [2]. It is necessary to take into account the current situation in the country and the world, associated with a high level of terrorism and extremism. To take into account the peculiarities of the modern generation, which is not used to being responsible for their actions, to analyze the consequences of their actions $[13,14,15]$. It is 
possible to form tolerant behavior within the walls of educational institutions during the training of a future specialist, taking into account the specifics of the multicultural environment of modern universities. Paying attention to the formation of those values and the translation of meanings that are inherent in people with a high level of communicative tolerance. To be guided by them, translating meanings, when choosing and updating values, constructing the life world in accordance with life meanings.

The analysis of theoretical and empirical studies devoted to the value-semantic sphere and communicative tolerance has shown that, despite the breadth of research issues, research on the peculiarities of life-meaning and value orientations of students with different levels of communicative tolerance is currently insufficiently presented in science.

\section{Research materials and methods}

The purpose of this study was to study the meaning-life and value orientations of psychology students with different levels of general communicative tolerance.

In our study, to confirm the hypothesis that there may be significant differences in life meaning and value orientations among psychology students with different levels of general communicative tolerance, we used a set of methods, including the method "General communicative Tolerance" by V. V. Boyko. In this method, tolerance is evaluated according to 9 signs of general communicative tolerance. The method of "Meaning-life orientations" in the modification of D. A. Leontiev. The Life-sense Orientations test allows you to study the features of the respondents ' semantic sphere and identify indicators to characterize their lifesense orientations. Questionnaire "Value orientations" by M. Rokich. The text of the methodology contains 2 lists of values, which are divided into terminal and instrumental.

\section{Results and discussions}

The study involved 60 students of the Don State Technical University (DSTU) and the Southern Federal University (SFU). Students of the humanities (psychologists) were selected: 35 girls and 25 boys. Age limits from 18 to 22 years. The study was conducted in several stages. At the first stage, a theoretical analysis of the problem of meaning-life and value orientations, their features, was carried out, the theoretical foundations of the concept of communicative tolerance and the features of its manifestation in students were studied. At the next stage, the planning of a scientific and empirical study was carried out. The goal, hypotheses and tasks were determined, and methodological tools for collecting empirical material were selected and developed. Further testing was conducted, using a group approach, among students of the humanities. Experimental data were obtained, generalized and analyzed. The sample of respondents was divided into 3 groups with high, medium and low levels of general communicative tolerance, according to the results of the methodology "General communicative tolerance" by V. V. Boyko. Statistical data processing was carried out, the results were summarized, and the conclusions of the study were formulated.

Further, according to the objectives of the study, the study of life-meaning orientations was carried out using the method of "Life-meaning orientations" in the modification of D. Leontiev, and the value orientations of students with different levels of general communicative tolerance, using the questionnaire "Value orientations" by M. Rokich.. The obtained results are processed statistically, the analysis of the obtained results is carried out, conclusions are drawn.

According to the method "General communicative tolerance" by V. V. Boyko, according to the data obtained, $33.3 \%(20 \mathrm{~h})$ of students have a high level of communicative tolerance, the average level is $45 \%(27 \mathrm{~h})$ and the low level is $21.7 \%(13 \mathrm{~h})$. Based on this, we further 
divided the entire sample into 3 groups and evaluated the features of life-meaning orientations among them. Group 1 consists of students with a high level of communicative tolerance, group 2 - students with an average level and group 3-students with a low level of communicative tolerance. According to the analysis of the presented data, it can be confidently stated that in group 1, the indicators for all 9 scales of the V. V. Boyko method are within the normal range and reflect normal communicative tolerance with respect to all its specific manifestations.

In group 2, the indicators on all scales of communicative tolerance are within the normal range, except for scale 8 - "Intolerance to physical or mental discomfort created by other people". This feature in communication is the lack of empathy and complicity with other people, the lack of tolerance for the discomfort created by other people, although the respondents themselves expect understanding and support. In group 3, the indicators were underestimated on a scale of 8 - "Intolerance to physical or mental discomfort created by other people" and on a scale of 2 - "Using oneself as a reference when evaluating the behavior and way of thinking of other people". These results reflect the desire of students from this group to evaluate the behavior of other people, the way of thinking and individual characteristics of their personality, setting a standard for themselves, judging a partner, guided by their habits, attitudes and moods, consider themselves "the ultimate truth". Along with this, showing intolerance to others, a lack of empathy and complicity with other people, but the expectation of understanding and support from others.

Thus, according to the method of "General communicative Tolerance" by V. V. Boyko, it is possible to diagnose tolerant and intolerant attitudes of the individual. In the framework of communicative tolerance, according to the author, it is possible to define situational, typological, professional and general tolerance. The analysis of the research results suggests that students with a high level of tolerance can easily build relationships with other people, get in touch with them and interact in communication processes; they accept the individuality of another person, are tolerant of opinions, beliefs, attitudes, and habits that differ from their own; have a high degree of tolerance for the uncomfortable states of others; have the ability to adapt to the characters, habits, attitudes, and claims of others; they do not have the desire to remake and re-educate a communication partner, which, of course, will have a positive impact on their future professional activities as practicing psychologists.

As a result of the diagnostic study conducted on the test Life Meaning orientations by D. A. Leontiev, the following results were obtained among the selected 3 groups of students. In Group 1, the primary place is occupied by values related to Goals. Accordingly, respondents with a high level of communicative tolerance have certain goals for the future, which give their lives meaning, direction and time perspective. Also, students from groups 1, 2 and 3 associate an important role with Locus of control-Life,-Life, this may indicate the belief that a person is given control over his life, free to make decisions and translate them into reality. Average scores were obtained on the Process and Result of Life scales. This indicates satisfaction with the life lived and its ongoing events. On the -ILocus of control-I scale, students from groups 2 and 3 scored low, which may indicate that none of the subjects in these groups yet consider themselves sufficiently strong personalities capable of controlling their lives. In groups 2 and 3, the most significant orientations are those related to Goals and Process, which indicates purposefulness, meaningfulness, focus and the presence of prospects for the future, and students from group 2 evaluate the process of their life as interesting, emotionally rich and filled with meaning. The data obtained by us in the course of the study on all scales of the D. A. Leontiev SOE methodology confirm significant differences in the Kruskal-Wallis H-criterion, where the indicators are considered reliable at $\mathrm{p}<0.05$.

According to the method of" value orientations " by M. Rokich, we obtained the following results regarding values-goals. Among the least significant value orientations (values-goals) 
in all 3 groups were: Productive life, the happiness of others and a financially secure life. The most important values for group 1 are those related to Love, Self-confidence, Health, and a Happy family life. For group 2 - Health, Love, Confidence, Happy family life, Development and Life wisdom. For 3 groups of students - Active activity, Life wisdom and Love, health, freedom. Among all 3 groups with high, medium, and low communicative tolerance, special differences are identified by values: Social Recognition, Development, Family life and Creativity.

The value of public recognition is clearly expressed in 2 groups of students with an average level of communicative tolerance. In 3 groups of students with low communicative tolerance, the value of Public recognition takes the last place in the choice of values. In group 1 of students with a high level of communicative tolerance, this value is not expressed. We assume that the high significance of this value indicates that a person is not satisfied with the current social situation and does not have enough attention, respect or understanding from others. The value of Development is highly important for groups 2 and 1 . This indicates that the students of these groups pay special attention to development, learning and are interested in it. The respondents have 3 groups, this value is in the average value. The significance of the value of Creativity is arranged as follows. The respondents of the 3 rd group attach special importance to creativity in their lives. Students of group 1 put Creativity on an average level. The respondents of the 2 nd group do not allocate a special place for creativity in life. We assume that such an arrangement of values may be related to the activity, age, social status, or gender of the subjects. According to the method of" value orientations " by M. Rokich, we obtained the following results regarding values-means. Among the least significant value orientations (values-means) in all 3 groups were: Intolerance to the shortcomings of others, Diligence. The value orientations associated with Education, Good Breeding and Independence are of the greatest importance for group 1. For the 2nd group - Good breeding, Independence and Strong will. For the 3rd group of students - Neatness, Good Manners and Rationalism. Among all 3 groups with high, medium, and low communicative tolerance, special differences are highlighted on the Education scale. Value Education occupies a primary place in the choice of values in 1 group of students with a high level of communicative tolerance. The respondents of group 2 placed this value at the average level of values, and students with a low level of communicative tolerance did not consider this value as significant in their lives. We assume that this arrangement of these values may be related to the age, social status, or gender of the subjects. The data obtained by us, in the course of the study on the Rokich's "Value Orientations" methodology, confirm significant differences in the Kruskal-Wallis H-criterion.

\section{Conclusion}

Thus, the hypothesis of the study that differences in meaning-life and value orientations can be found in students with different levels of general communicative tolerance is confirmed. Analysis of the results using the method of" communicative tolerance " by V. Boyko showed that students with a high level of communicative tolerance can easily build relationships with other people, get in touch with them and interact in communication processes; they accept the individuality of another person, are tolerant of opinions, beliefs, attitudes, and habits that differ from their own; have a high degree of tolerance for the uncomfortable states of others; have the ability to adapt to the characters, habits, attitudes, and claims of others; they do not have the desire to remake and re-educate a communication partner, which, of course, will have a positive impact on their future professional activities as practicing psychologists. According to the results of the D. A. Leontiev's method of SOE, the respondents of group 1, psychology students with a high level of communicative tolerance, have a predominant orientation related to the Goal, that is, they are focused on the future. Life-meaning 
orientations in the group with medium and low levels of communicative tolerance are practically the same. In these groups, the orientations associated with c Locus of control-Life and Process-predominate. The minimum values among the entire group of students were reached by life-sense orientations associated with the "Result" and "Locus of control-I". In our opinion, this may be due to the age characteristics of the students. Since at this age, the main orientation of students is for the future and not yet great life experience and achievements. Value orientations (terminal values) associated with Love, Self-confidence, Health, and a Happy family life are of the greatest importance for students with a high level of communicative tolerance. The value orientations (instrumental values) associated with Education, Good Breeding and Independence are of the greatest importance for group 1. This may indicate the formation of those values and meanings that contribute to the development of a mature personality, with an optimal level of tolerant consciousness, which includes value-semantic attitudes towards dialogue, equal communication, cooperation, joint creativity, and the desire for mutual self-expression. Further attention should be paid to the problem of the formation of communicative tolerance as a professionally important quality of a young specialist's personality.

\section{References}

1. A.G. Asmolov, Questions of psychology 4, 3-12 (2003).

2. I.V. Abakumova, Materials of the regional scientific-practical seminar. Publishing house, 98-103 (2002)

3. D.A. Leontiev, Voprosy psikhologii 5, 3-16 (2009).

4. D.A. Leontiev, Test of life-meaning orientations (LSS, M., 1992).

5. A.K. Belousova,O.V. Barsukova, Y.A. Tushnova, M.A.Vyshkvyrkina, E.P. Krischenko, N.N. Mozgovaya, T.V. Pavlova, J.A. Mochalova, Mediterranean Journal of Social Sciences. MCSER Publishing, Rome-Italy 6 (4), 238-241 (2015). doi:10.5901/mjss.2015.v6n4s4p

6. O. Nikolenko, L. Zheldochenko, N. Lomova, E3S Web of Conferences 175, 15029 (2020). doi.org/10.1051/e3sconf/202017515029

7. L. Zheldochenko, O. Nikolenko, E3S Web of Conferences 210, 18079 (2020). doi.org/10.1051/e3sconf/202021018079

8. L. Zheldochenko, O. Nikolenko, E3S Web of Conferences 210, 22001 (2020) doi.org/10.1051/e3sconf/202021022001

9. A.Korochentseva, E.Suroedova, N.Khachaturyan, O.Nikolenko, SHS, Web of Conferences 70, 08020 (2019). doi.org/10.1051/shsconf/20197008020

10. D.F. Dautov, O.F. Nikolenko, Y.V. Rashchupkina, N.V. Lomova, Y.A. Tushnova, Cognitive Maps of Participants in Joint Mental Activity, The 2nd International Conference on Education Science and Social Development, Changsha, China, (2019) doi.org/10.2991/essd-19.2019.47

11. Ju. Rashupkina, O. Nikolenko, etc., Specific features of students 'personal maturity and personal immaturity depending on their social status, In the collection: (INTED 2017), 11th International Technology, Education and Development Conference Conference proceedings, Edited by L. Gómez Chova, A. LópezMartínez, I. Candel Torres; IATED Academy. 6300-6303 (2017)

12. V.V. Boyko, Energy of emotions in communication: a look at yourself and others (M., 1996). 
13. V. Pishchik, Z. Spivachuk, The uniqueness of values and personal traits of Generation $Z$ students in the innovative educational space of the southern region of Russia, Innovative Technologies in Science and Education (ITSE-2020), E3S Web Conf. 210, 18035 (2020). doi.org/10.1051/e3sconf/202021018035

14. V. Pishchik, A. Belousova, L. Ryumshina, The relationship of generations representatives in the educational environment, (EDULEARN18), Proceedings 10th International Conference on Education and New Learning Technologies, 1782-1786 (2018. )doi: 10.21125/edulearn. 2018. 0524

15. A.K. Belousova, O.V. Barsukova, Y.A. Tushnova, M.A. Vyshkvyrkina, E.P. Krischenko, N.N. Mozgovaya, T.V. Pavlova, J.A. Mochalova, Mediterranean Journal of Social Sciences, MCSER Publishing, Rome-Italy 6 (4) S4, 238-241 (2015). doi:10.5901/mjss.2015.v6n4s4p 